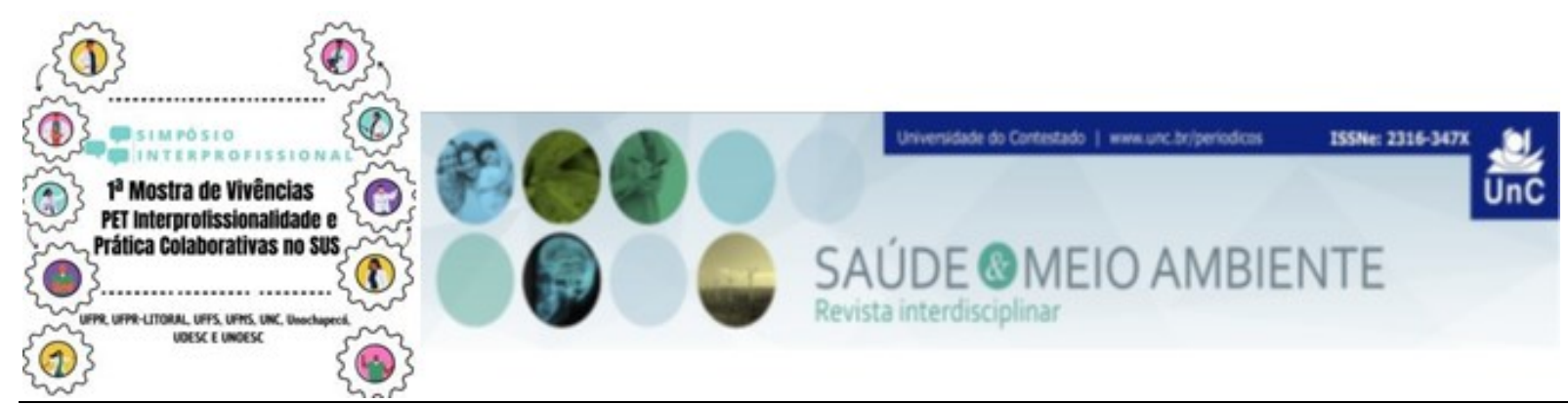

\title{
A IMPORTÂNCIA DA ETAPA DE AVALIAÇÃO COMO FERRAMENTA PEDAGÓGICA NO GRUPO PET-SAÚDE INTERPROFISSIONALIDADE ${ }^{1}$
}

\author{
Lucas Gerke Cordeiro² \\ Rhandra Grubert Gonzaga Maciel ${ }^{3}$ \\ Thaylla Mwryha Maciel Bueno ${ }^{4}$ \\ Andressa Conceição Contò ${ }^{5}$ \\ Camila de Carvalho Krugel $^{6}$ \\ Daniela Bruno dos Santos ${ }^{7}$ \\ Rodrigo Guimarães dos Santos Almeida ${ }^{8}$
}

\begin{abstract}
RESUMO
Introdução: A estrutura de trabalho-educação apresentada pelo Marco para a Ação em Educação Interprofissional e Prática Colaborativa OPAS/OMS, oportunizou a elaboração de novas propostas teóricas e práticas para formação em saúde, de modo a promover uma singularidade na abordagem de ensino para graduandos e profissionais da saúde. Ao se considerar a relevância do exercício pedagógico utilizado nos grupos PET-Saúde EIP, de planejamento, execução, avaliação e monitoramento no decorrer do trabalho, destaca-se a importância da etapa de avaliação. O planejamento teórico e a implementação na prática, proporciona o engajamento pessoal das percepções individuais dos membros, sejam elas, boas ou ruins, no dia a dia das atividades com o propósito de proporcionar melhorias no processo de trabalho. Objetivo: Relatar o impacto da implementação de uma abordagem pedagógica na avaliação do processo de trabalho para o amadurecimento coletivo de grupo PET/Saúde de Campo Grande - MS. Metodologia: Utiliza-se a

${ }^{1}$ Fonte de financiamento: Programa de Educação pelo Trabalho para a Saúde - PET

Saúde/Interprofissionalidade 2019-2021 (Edital no 10 de 23 de julho de 2018, Ministério da

Saúde/Secretaria de Gestão do Trabalho e da Educação na Saúde).

${ }^{2}$ Estudante no PET. Graduando em Nutrição pela Universidade Federal de Mato Grosso do Sul. Mato

Grosso do Sul. Brasil. E-mail: lucasgerkee@hotmail.com.

${ }^{3}$ Estudante no PET. Graduando em Nutrição pela Universidade Federal de Mato Grosso do Sul. Mato Grosso do Sul. Brasil. E-mail: rhandrag@gmail.com

${ }^{4}$ Estudante no PET. Graduando em Nutrição pela Universidade Federal de Mato Grosso do Sul. Mato Grosso do Sul. Brasil. E-mail: thaylla.maciel@ufms.br.

${ }^{5}$ Estudante no PET. Graduando em Nutrição pela Universidade Federal de Mato Grosso do Sul. Mato Grosso do Sul. Brasil. E-mail: andressaconto@gmail.com.

${ }^{6}$ Estudante no PET. Graduando em Nutrição pela Universidade Federal de Mato Grosso do Sul. Mato Grosso do Sul. Brasil. E-mail: cahkrugel@gmail.com.

${ }^{7}$ Estudante no PET. Graduando em Nutrição pela Universidade Federal de Mato Grosso do Sul. Mato Grosso do Sul. Brasil. E-mail: daniela.bsantos77@gmail.com.

${ }^{8}$ Coordenador do grupo PET. Docente de enfermagem na Universidade Federal de Mato Grosso do Sul. Mato Grosso do Sul. Brasil. E-mail: rgclaretiano@gmail.com.
\end{abstract}


dinâmica de grupo: "Que bom! Que pena! Que tal?"1 para avaliação processual pósintervenção. A atividade é conduzida por um aluno mediador, previamente escolhido, e acontece sempre ao fim das reuniões, de forma a conduzir um fechamento do dia após as atividades propostas e os encaminhamentos serem devidamente concluídos. Por meio de uma roda de conversa, pede-se para cada integrante do grupo relate suas percepções e reflexões acerca do que aconteceu no dia, tanto a respeito das atividades feitas, quanto ao trabalho em equipe, planejamento, assiduidade de membros ou comportamentos, sendo o relato norteado dinâmica grupal citada, com ênfase na determinação de soluções para o aperfeiçoamento do processo de trabalho. Resultados: A estratégia pedagógica adotada trouxe melhora na confiança entre todos os integrantes, incentivou a participação mais ativa de todos na captação de ideias e percepções que poderiam contribuir em futuras ações. Dinamizou o trabalho em grupo, cessou a atitude passiva de alguns membros, evidenciou a importância do aumento do protagonismo dos acadêmicos e o seu empoderamento para a tomada das decisões. Considerações Finais: $O$ momento de avaliação em forma de dinâmica permitiu maior compartilhamento de ideias, incentivou a atuação de estudantes e garantiu uma maior interação entre os participantes, professores e preceptores. A utilização desta ferramenta trouxe um enriquecimento enorme para o grupo quanto à comunicação, harmonia entre os integrantes, clareza de opiniões e dos papéis de cada um, além de, romper a hierarquização que havia entre preceptores e alunos, o que favoreceu a relação e o trabalho interpessoal na equipe.

Palavras-chave: Interprofissionalismo. Prática Colaborativa. Aperfeiçoamento de Equipe.

\section{REFERÊNCIAS}

1. Berkenbrock VJ. Dinâmicas para encontros de grupo: para apresentação, intervalo, autoconhecimento e conhecimento mútuo, amigo oculto, despertar, avaliação e encerramento. 12. Ed. Petrópolis: Vozes; 2014. 